Disclosure of Interests: Alesia Sadosky Shareholder of: Own stock in Pfizer Inc, Consultant of: I am an employee with the consulting firm Apperture Health, Employee of: I am retired from Pfizer Inc, Patricia Schepman Shareholder of: Owns shares in Pfizer Inc, Employee of: Employee of Pfizer Inc, Sheena Thakkar Shareholder of: Owns shares of Pfizer Inc, Employee of: Employee of Pfizer Inc, Rebecca Robinson Shareholder of: Owns shares of Eli Lilly and Company, Employee of: Employee of Eli Lilly and Company, Craig Beck Shareholder of: Owns shares of Pfizer Inc, Employee of: Employee of Pfizer Inc

DOI: 10.1136/annrheumdis-2021-eular.534

\section{AB0036 APPA (APOCYNIN AND PAEONOL) REDUCES ROS PRODUCTION AND SENESCENCE IN HUMAN ARTICULAR CHONDROCYTES}

M. Fernandez-Moreno ${ }^{1}$, N. Larkins ${ }^{2}$, A. Reynolds $^{2}$, T. Hermida Gómez ${ }^{1,3}$, F. J. Blanco ${ }^{1}{ }^{1}$ Instituto de Investigación Biomédica de A Coruña (INIBIC). Complexo Hospitalario Universitario de A Coruña (CHUAC), Sergas. Universidade da Coruña (UDC). CICA-INIBIC., Servicio de Reumatología., A Coruña, Spain; ${ }^{2} A K L$ Research \& Development, Stevenage Bioscience, Stevenage SG1 2FX., United Kingdom; ${ }^{3}$ Centro de Investigación Biomédica en Red, Bioingenieria, Biomatereial y Nanomedicina, (CIBER-BBN)., Madrid, Spain

Background: Disease modification is not yet possible for osteoarthritis (OA) Mitochondrial ROS and pro-inflammatory cytokines are involved in the pathogenesis of OA and are potential therapeutic targets. APPA, a combination of apocynin (AP) and paeonol (PA), has the potential capacity to modulate synthesis of pro-inflammatory stimuli.

Objectives: To investigate the anti-inflammatory effect of APPA in human articular chondrocytes and cartilage.

Methods: Tissue and chondrocytes from human OA cartilage were isolated. The effect of APPA on chondrocyte viability was analyzed using MTT. IL-1 $\beta 10 \mathrm{ng} / \mathrm{mL}$ and LPS $10 \mathrm{ng} / \mathrm{mL}$ were used as pro-inflammatory stimuli. ROS production was evaluated by flow cytometry using DCFH-DA and MitoSoxRed. The percentage of senescent cells was evaluated through the quantification of Fluorescein di- $\beta$-D-galactopyranoside (FDG) by flow cytometry. The effect of APPA on gene expression of pro-inflammatory cytokines (IL-8 and TNF- $\alpha$ ) and enzymes degrading cartilage (MMP-13 and MMP-3) were analyzed in chondrocyte and cartilage by RT-PCR. Quantification of Toluidine Blue (TB) staining in cartilage was performed to evaluate proteoglycans content using software ImageJ/Fiji. Release of Glycosaminoglycan (GAGs) into the supernatant was quantified using BlyscanTM Glycosaminoglycan assay. Statistical analyses were performed with GraphPad Prism v6.

Results: Chondrocytes, incubated in presence of APPA $10 \mu \mathrm{g} / \mathrm{mL}$ for $24 \mathrm{~h}$ had viability $>85 \%$, reduced cytoplasmic ROS $(p=0.028)$ and mitochondrial anion superoxide production induced by LPS $10 \mathrm{ng} / \mathrm{mL}(p=0.057)$. Chondrocytes incubated in presence of APPA $10 \mu \mathrm{g} / \mathrm{mL}$ for 2 hours contained significantly fewer senescent cells $(p=0.0079)$. APPA significantly reduced the gene expression induced by IL-1 $\beta 10 \mathrm{ng} / \mathrm{mL}$ in chondrocytes of $I L-8, T N F-\alpha, M M P-13$ and MMP-3. Cartilage incubated with APPA 60 and $100 \mu \mathrm{g} / \mathrm{mL}$ for $48 \mathrm{~h}$ showed decreased the MMP-3 gene expression induced by IL-1 $\beta$ ( $p=0.021$ and $p<0.0001$ respectively). Quantification of TB showed that APPA 60 and $100 \mu \mathrm{g} / \mathrm{mL}$ during $48 \mathrm{~h}$ increased the proteoglycans in intermedial layer, which had been decreased through the incubation with IL-1 $\beta \quad(p=0.0018$ and $p=0.018$ respectively). Quantification of release GAGs into the supernatant decreased significantly when the cartilage explants were incubated for $48 \mathrm{~h}$ in presence of APPA $100 \mu \mathrm{g} / \mathrm{mL}(p=0.028)$.

Conclusion: APPA has a clear anti-inflammatory effect on human articular chondrocytes, and could reduce extracellular matrix degradation of cartilage. This could be mediated by the capacity to modulate ROS production and reduce senescence.

Disclosure of Interests: Mercedes Fernandez-Moreno: None declared, Nicholas Larkins Shareholder of: I am a shareholder in AKL Research and Development Ltd, Alan Reynolds Shareholder of: I have share options in AKL Research and Development Ltd, Speakers bureau: I have not been a paid speaker for a pharma company - at least not since 2008 whichl think is outside the scope of this, Consultant of: The last time I was a paid consultant was in 2017 when I acted as a consultant for Avillion and Norgine, Employee of: I am also an employee of AKL Research and Development Ltd, Tamara Hermida Gómez: None declared, Francisco J. Blanco Speakers bureau: Lilly

Pfizer

Sanofi

Galapagos, Consultant of: Lilly

Pfizer

Sanofi

Galapagos, Grant/research support from: Lilly

MSD

Merck Serono

Pfizer

Pierre-Fabra

Roche
Sanofi

Servier

UCB

Abbvie

Amgen

Bioiberica

Bristol Mayer

Celgene

Celltrion

Cellerix

Grunenthal

Gebro Pharma

AKL Research and Development Ltd

DOI: 10.1136/annrheumdis-2021-eular.2027

\section{AB0037 UNDIFFERENTIATED ARTHRITIS}

O. Jomaa ${ }^{1}$, J. Mahbouba ${ }^{1}$, S. Zrour ${ }^{1}$, I. Bejia ${ }^{1}$, M. Touzi ${ }^{1}$, N. Bergaoui ${ }^{1}$.

${ }^{1}$ University Hospital Fattouma Bourguiba Monastir, TUNISIA, Rheumatology

Department, Monastir, Tunisia

Background: Early recognition and treatment of inflammatory arthritis is imperative for the further course of the disease.

Objectives: This study aims to determine the evolution of undifferentiated arthritis observed in rheumatology.

Methods: Retrospective descriptive study which collects patients files identified as undifferentiated Arthritis and followed in the Rheumatology Department at Fattouma Bourguiba Hospital Monastir TUNISIA over a period of 15 years (2005, 2019). Epidemiological, clinical, paraclinical, and evolutionary data were collected and analyzed.

Results: 99 files were analyzed. The average age was $42.06 \pm 15.56$; they were 42 males and 57 females with an average body mass index of $27 \pm 6.1 \mathrm{Kg} / \mathrm{m} 2$. The reason leading to consultation was, polyarthritis (37), oligoarthritis (27), mono-arthritis (21), and polyarthralgia (15). The median time to visit was 60 days [ 15 days, 3 months]. The median number of painful joints and swollen joints was $4[2,8]$, and $2[1,4]$ respectively. The mean duration of morning derusting was $34.8 \pm 24.4$ minutes. Extra-articular manifestations were: a dry syndrome (22), a rheumatoid nodule (2), and serosal damage (1). Anemia (52 patients), leukopenia (6 patients), and lymphopenia (13 patients) were found in the blood cell count with a biological inflammatory syndrome in most patients (72/99). The immunology results showed: positive anti-nuclear antibodies (15/99), positive Anti-Citrullinated Protein Antibodies (9/99) and positive rheumatoid factor (8/99) 31 patients had standard radiological signs represented mainly by joint pinching and erosions. A joint puncture was done in 36/99 revealing inflammatory fluid in most cases. After an average follow-up of 1047 days [365, 1460]. undifferentiated arthritis was classified as rheumatoid arthritis (RA) (23), spondyloarthritis (SpA) (10), connective tissue disease (11), Crystalline Arthritis (5), and paraneoplastic arthritis (2). One patient had self resolution of symptoms and 38 remain undifferentiated.we found that the more the patients were seropositive, the more likely to develop Rheumatoid Arthritis $(p=0.001)$, the more there was disorder in the blood cell count, the more the evolution was towards connective tissue disease (0.01), The more male patients were, the more likely to develop SpA $(p=0.04)$. The patients management was mainly based on: analgesics (94), systemic corticosteroids (57) with a mean dose of $10.89 \pm 5.8 \mathrm{mg} /$ day. The use of Methotrexate and antimalarial drugs was noted in 18 and 15 patients respectively.

Conclusion: Follow-up of patients with undifferentiated arthritis leads to a definite inflammatory rheumatism diagnosis in $61.6 \%$ of cases. Our data indicate that seropositive patients with chronic symptoms carry an increased risk of developing Rheumatoid Arthritis $(P=0,001)$. Clinical, biological and genetic data can help the health care provider to predict future outcomes.

REFERENCES:

[1] DOI: 10.1007/s00132-018-3539-2.

Disclosure of Interests: None declared

DOI: 10.1136/annrheumdis-2021-eular.2309

\section{AB0038 CIRCULATING MICRORNAS IN HAND OSTEOARTHRITIS}

A. Pekacova $^{1,2}$, J. Baloun ${ }^{1}$, O. Sleglova ${ }^{1,2}$, O. Růžičková ${ }^{1,2}$, J. Vencovský1,2, K. Pavelka ${ }^{1,2}$, L. Šenolt ${ }^{1,2}$. Institute of Rheumatology, Department of Rheumatology, Prague, Czech Republic; ${ }^{2}$ First Faculty of Medicine Charles University, Department of Rheumatology, Prague, Czech Republic

Background: microRNAs (miRNAs) are small non-coding RNAs that can ignite the degradation of mRNAs or inhibit the protein translation and are therefore essentia for several physiological and pathological functions. miRNAs can regulate up to 60 $\%$ of human mRNA, including genes related to cartilage development, homeostasis, and OA pathology. For example, miR-9 inhibits matrix metalloproteinase 13 